\title{
Aspects regarding the research in the field of electric vehicles implementation in the context of the sustainable development of the European road transport system
}

\author{
Gheorghe Neamțu ${ }^{1}$, Andrei Alexandru Boroiu ${ }^{2}$, Aurel Mihail Ţîțu ${ }^{3,4,5}$ \\ ${ }^{1}$ Polytechnic University of Bucharest, 54 Splaiul Independenţei, Sector 5, Bucharest, \\ Romania \\ ${ }^{2}$ University of Pitești, 1 Târgul din Vale Street, Pitești, Argeș, Romania \\ ${ }^{3}$ Lucian Blaga University of Sibiu, 10 Victoriei Street, Sibiu, Romania \\ ${ }^{4}$ The Academy of Romanian Scientists, 54 Splaiul Independenţei, Sector 5, Bucharest, \\ Romania \\ ${ }^{5}$ Romanian Association for Alternative Technologies Sibiu, 10 Victoriei Street, Sibiu, \\ Romania \\ E-mail: geluneamtu@yahoo.com, andrei.boroiu@upit.ro, mihail.titu@ulbsibiu.ro
}

\begin{abstract}
The scientific paper presents a concrete research carried out by the authors in order to implement some concepts of a technical nature, so that those interested in this field can get acquainted about a certain way of exposing the problems regarding the actions taken by the European authorities, regarding the implementation of electric vehicles at the level of some EU states, in the context of the sustainable and durable development of the European road transport system. Below we present a technical and managerial study with engineering nuances, through which readers can look at and understand the concept of sustainable development of this sector in a global context, through which we will demonstrate the efficiency and effectiveness of the Project of the Electric Vehicle Network in Urban Europe - URBACT II, (EVUE) [11][12], a research project carried out at European Union level in the field of electromobility and the measures taken to reduce pollution in 9 European cities. The research was carried out in public private partnership (cPPP) and was funded by the European Investment Bank (EIB). The initiative was launched in 2009 as a constituent element of the challenge: "Intelligent, green and integrated transport" under Horizon 2020 programme [9] as a result of the global economic crisis of 2008 and was completed in 2012 through 113 collaborative research projects [3] [12].

The paper highlights the achievements and shortcomings of this initiative, and finally the conclusions and subsequent directions of research in the field approached are presented.

Keywords: intelligent transport system, information technology, connected and automated mobility, telematics systems, sustainable development, management
\end{abstract}

\section{Introduction}

"Mobility and transport are important to all of us. From daily commuting to work, visiting family and friends, tourism, to the smooth running of the world's supply chains of goods to our shops and industrial production, mobility is a contributing factor in our economic and social life. The free movement of people and goods across internal borders is one of the fundamental freedoms of the European Union (EU) and its single market. Travelling in the EU has led to increased cohesion and 
the strengthening of European identity. As the second largest spending area for European households, the transport sector contributes $5 \%$ to European GDP and directly employs around 10 million workers" [7].

Fossil fuel natural resources are expected to run out in the next 35-40 years. In this sense, humanity will have to find alternatives for mobility. Alternative fuels will have to replace those based on carbon. Worldwide, environmentally friendly vehicles, electric vehicles, are growing more and more.

"Although it brings many benefits to its users, mobility also involves costs for our society. These include greenhouse gas emissions, air, noise and water pollution, but also road and other accidents, congestion and biodiversity loss, all of which affect our health and well-being. The political efforts and measures so far have not yet sufficiently addressed these costs. Greenhouse gas emissions from the transport sector have increased over time and currently account for no less than a quarter of the EU total" [7].

It takes humanity to find other energy resources to secure its mobility needs.

In other words, specialists and researchers have the mission to find current transport variants that do not pollute the environment and that do not affect human health, and this can be achieved through an increase in the energy efficiency of the fuels burned in the thermal engines of the means of transport, the use of more fuel-efficient, ecological, clean vehicles, the use of alternative energies for travel, the orientation of the mobility needs of the society towards other transport systems than the road ones and last but not least, the use of ecological intermodal transport, the permanent reduction of waste of any kind resulting from the production or decommissioning of degraded, old, outdated, physically and morally worn means of transport. Technological evolution allows it to do so. The key to this problem is the electric vehicle, which is the sustainable and hundredth-lasting solution to the problem of human mobility.

Electric vehicles appear in land transport systems as an alternative to the conventional vehicle that has become increasingly polluting for the environment.

"Same as with renewable energy over the last decade, the automotive industry is currently investing heavily in the emergence of low and zero-emission vehicle technologies such as electric vehicles" [6].

The initiative on the development of environmentally friendly means of transport, of the so-called 'green, environmentally friendly' vehicles, has long been on the agenda of European parliamentarians. One of the most important initiative in this direction was taken at European level by the Commission in September 2007, when the Green Paper was launched, entitled "Towards a new culture of urban mobility" [1].

The initiative supports the process of decarbonizing transport systems across European cities.

"The main environmental problems in cities are related to the predominant use of oil as a fuel, which generates $\mathrm{CO}_{2}$ air pollutants and noise" [5].

"Transport is the most difficult sector to manage in terms of $\mathrm{CO}_{2}$ emissions. Despite advances in automotive technology, the increase in traffic and the jerky way - "off-on" - of driving the car in urban areas show that cities are a major and growing source of $\mathrm{CO}_{2}$ emissions that contribute to climate change. Climate change is causing dramatic changes in the global ecosystem and urgent action is needed to be taken to keep those consequences at a manageable level" [5].

\section{Electric Vehicle Network Project in Urban Europe - URBACT II, (EVUE)}

"Electric vehicles in urban Europe focus on developing integrated, sustainable strategies and dynamic driving techniques in cities to promote the use of electric vehicles. Urban initiatives to encourage the public and businesses to use electric vehicles will contribute to the EU's clean air and car fleet objectives, making cities more attractive and competitive" [11].

As regards these projects in the field of electromobility, the research was carried out in public private partnership (cPPP) and was financed from the European Investment Bank (EIB), research grants from the EU's Seventh Framework Programme, but also from the private sector. The total value 
of this initiative cost the EU $€ 5$ billion and was launched in 2009 as a constitutive element of the challenge: "Smart, green and integrated transport" [3] under Horizon 2020 programme.

The initiative was taken as a result of the global economic crisis of 2008 and was completed through 113 collaborative research projects.

The interested parties for this initiative were the European technology platforms ERTRAC, EpoSS, other smart grids brought together in the European Association of Green Initiatives (EGVIA). The European Commission services DG RTD, DG MOVE, DG Connect were also included [3].

The initiative aims to address the systemic challenges of decarbonization of road transport, contributing to the transition to a green road transport, while stimulating the innovative power and competitiveness of the EU.

"EVUE will exchange and disseminate solutions to key barriers such as public resilience, lack of infrastructure, rapid technology change and outdated economic modeling" [11].

The innovative part of this initiative has created around 12 million jobs at European level and has had a significant impact on economic growth and international trade.

The research on the electric vehicles and their infrastructure was carried out for two and a half years, within the project Electric Vehicle Network in Urban Europe - URBACT II, (EVUE) and had two phases: phase I - development (November 24, 2009 - May 24, 2010) and phase II implementation starting on July 19, 2010 [3] [12].

The main objective of the research project was to change the mentality of citizens regarding road traffic and public transport, in order to use environmentally friendly means of transport, especially electric ones, to reduce pollution produced by road traffic.

The project was attended by the European cities of Beja, Frankfurt, Katowice, Lisbon, London, Madrid, Oslo, Stockholm and a city in Romania, Suceava city [3] [12].

For the development of the project, they had a series of trainings, visits to the urban environment, meetings between experts and bilateral interpretations.

Four themes were addressed within the project, through which the problems encountered to speed up the implementation of electromobility were made known, namely [3] [12]:

1. Business prototypes;

2. Public procurement of electric vehicles;

3. Charging infrastructure serving the charging of the electric accumulators of these vehicles;

4. Ways to raise awareness and convince people to purchase and use electric vehicles.

The interested people of these research programmes were, according to [3] [12]:

$\checkmark$ European motor vehicle manufacturers;

$\checkmark$ Electricity suppliers;

$\checkmark$ Providers of charging infrastructure;

$\checkmark$ Transport operators;

$\checkmark$ Users.

"Interested people can be considered key players with a particular interest in the development of a particular policy or measure. It is clear that the effectiveness (and efficiency) of a given strategy depends on the degree of understanding between the interested people concerned. Cooperation and the development of an integrated approach is therefore a necessary condition for success" [3] [12].

The research carried out at European level in order to implement electromobility was carried out in the form of projects, which we present below.

\subsection{Research Project Peugeot Spain E MOBILITY}

The business project consists of a package in which everything is included. Through this mobility package, the customer is paying for less than EUR 500 per month for an electric vehicle [3] [12].

The offer consists of a lease for a period of 48 to 60 months which includes $10.000 \mathrm{~km}$ per year and a subsequent return offer [3] [12].

The offer is also available in the leasing version. 
The data on the constituent elements of the electromobility research project by Peugeot Spain E MOBILITY are shown in Figure 1.

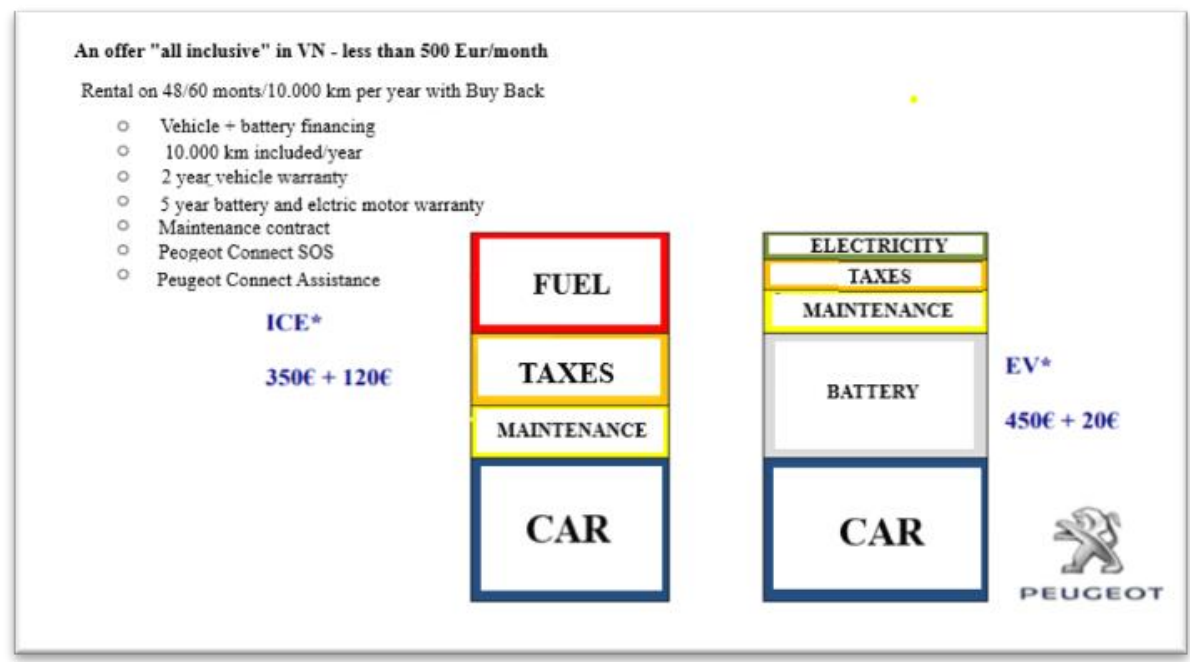

Figure 1. European research project Peugeot Spain E MOBILITY [3] [12].

\subsection{Renault ZE research project}

To increase users' appetite for the electric motor vehicle, Renault offers them the reduction of the direct costs by purchasing such units without the electric battery. Instead, owners of electric vehicles will rent the electric battery at a price between 45 and 80 Euros per month. In this case, we specify that the high price of electric motor vehicles is given by the high cost of accumulators.

"Although the total costs generated over time are still significant, this approach minimizes the initial purchase price and reduces the financial risk of electric vehicle owners by the fact that the battery is guaranteed for life" [3] [12].

In Figure 2.2 the research project in the field of electric vehicles, carried out by Renault ZE, is schematically represented.

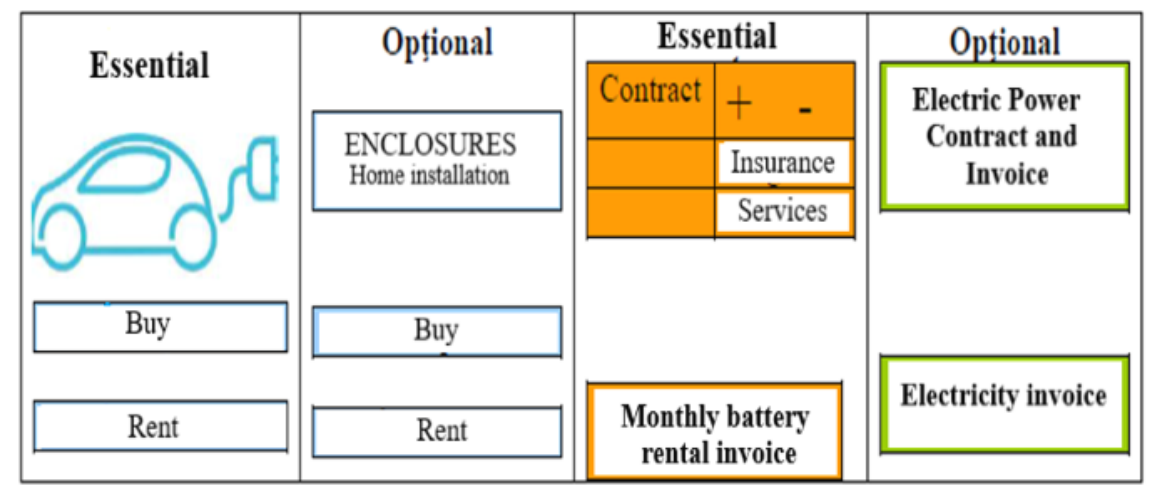

A stop shopping in the Renault network

Figure 2. Presentation scheme of the Electric Vehicle Research Project, Renault ZE [3] [12]. 


\subsection{MOBI.E research project, Portugal}

The European electromobility research project in Portugal was launched by the government of Portugal in the form of a working group at the beginning of 2008. It later became a national programme for electric mobility and it was titled MOBILE.

MOBI.E is an open model, suitable for any business or market format. MOBI.E is a systems integrator, based on the following operating principles [3] [12]:

$\checkmark$ Interfunctionality - an integrated and fully interoperable system that includes energy traders, charging station operators and motor vehicle manufacturers;

$\checkmark$ Scalability - a "system in systems" approach, thus solving the problem of lack of communication between the various existing systems (a vehicle can be charged at any electric charging station, anywhere in Europe - universal compatibility);

$\checkmark$ Networked system - It is possible to charge the battery with electricity with a single MOBI.E card supplied to any retailer at any charging station. All the infrastructure is connected to the network, each new addition reinforces previous investments, and MOBI.E contributes to a faster development of the system;

$\checkmark \quad$ Integration of other services - it can integrate other services such as tolling, parking, public transport or car "sharing" systems. This means that a MOBI.E card can be used as a payment card for all mobility needs;

$\checkmark$ Intelligence - The Mobility Intelligence Center (CIM) includes all the flows of financial resources, information and energy between the users and companies involved, playing the role of the central clearing house. This mechanism reduces transaction costs and avoids duplication of systems.

Figure 3 shows schematically the Electric Vehicle Research Project MOBI.E from Portugal.

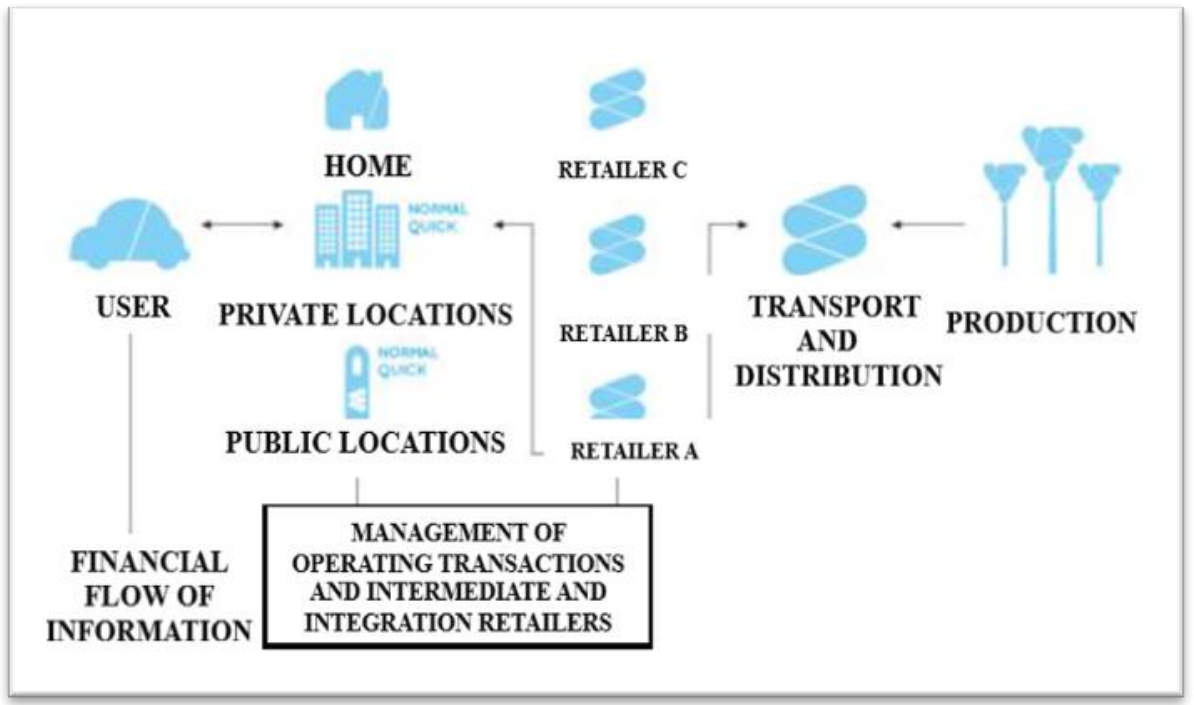

Figure 3. Research project in the field of electric vehicles, MOBI.E from Portugal [3], [12].

\subsection{RWE E-MOBILITY research project, Germany}

The German business model in the field of electromobility includes the whole system, including the consumers, but also the customers with their own fleets of electric vehicles.

$\checkmark$ "This strategy is based on corporate partnerships and technological leadership" [3] [12].

$\checkmark$ In the author's view, technological leadership represents [3] [12]:

$\checkmark$ Separate smart charging infrastructure;

$\checkmark$ Standardization determined by electric vehicles/ interface of charging stations;

$\checkmark$ Competitive margins through the advantageous infrastructure system (development/cooperation for infrastructure); 
$\checkmark$ Convincing important partners about charging stations in the most attractive locations;

$\checkmark$ Sharing common marketing costs for infrastructure/by accepting the common brand/marketing;

$\checkmark$ Complete information about e-mobility;

$\checkmark$ Concrete product offers for final consumers;

$\checkmark$ Targeted media and advertising effort;

$\checkmark \quad$ Joint marketing with OEMs and other partners.

RWE is a German utility company (electricity field), based in Essen. The company believes that EMOBILITY services address a spectrum of policies and measures that adjust the preconditions specific to electric vehicles and infrastructure by including a "sharing" for a unit of this type, but also different approaches to parking management.

"These services do not necessarily have to be implemented by public authorities, as many third parties want to explore the opportunities associated with increasing the number of electric vehicles. These players want to implement new concepts to offer a wide range of mobility services that facilitate the penetration of electric vehicles through financial gains" [3] [12].

Figure 4 shows schematically the Electric Vehicle Research Project, RWE E-MOBILITY from Germany.

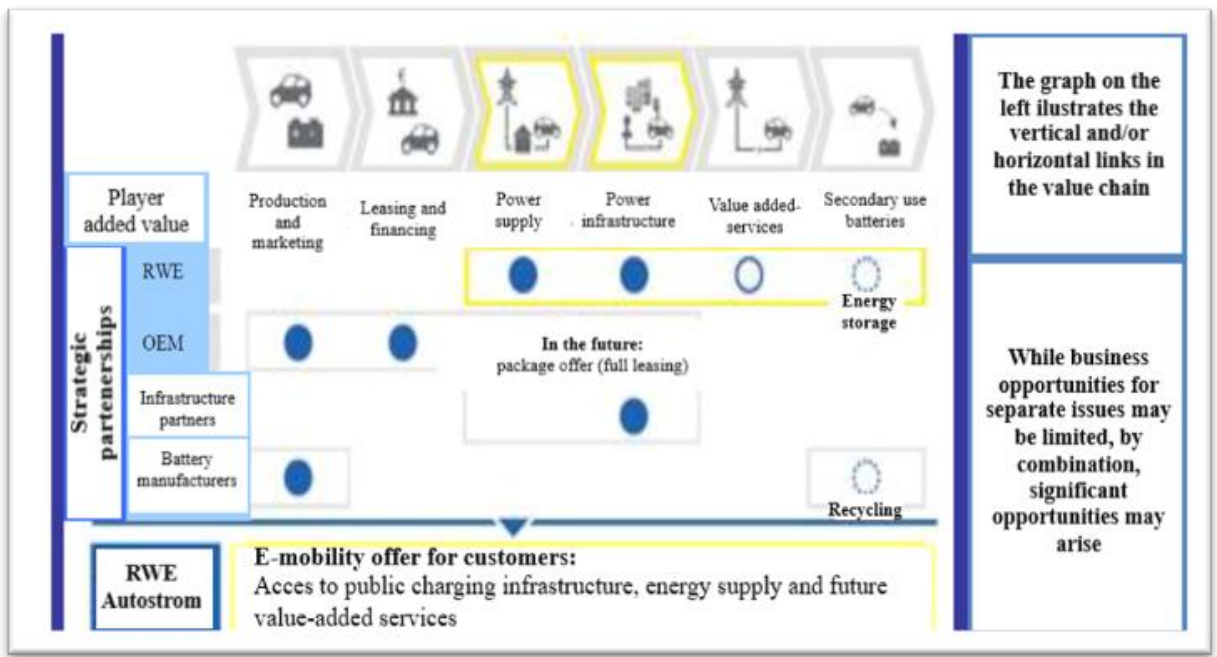

Figure 4. Electric vehicle research project, RWE E-MOBILITY from Germany [3] [12].

\subsection{Car2go research project, Holland}

The research project was carried out in the Dutch city of Amsterdam with a fleet of 300 electric cars Smart Fortwo, made available by the large German car manufacturer Daimler-Benz at request, without being returned. In Amsterdam, there are other ongoing electromobility projects (bicycle programmes and "sharing" for motor vehicles), highly appreciated by the inhabitants of the city.

"The innovative mobility programme complements these existing transport systems by providing a service for short and spontaneous journeys on a single stretch of road with electric vehicles, which could pave the way for a better modal division of urban transport" [3] [12].

The project covers an area of approx. $80 \mathrm{~km}^{2}$, covering large areas of the urban territory.

Basically, the green motor vehicles are taken by the customers from the provider, they solve their mobility needs, after which they return with the vehicle to make the payment of the rental. The motor vehicles can be rented and then left anywhere, including in the 36 parking spaces in the central area of the metropolis, marked with the inscription of the Car2go project. To solve this problem, six "Q-Park" garages were built. 
"There is no need for the rental to be completed every time at a charging station. However, if the battery capacity (charge level) is less than $20 \%$, rentals must be completed at one of the charging stations, which are indicated by the on-board navigation system. If the battery charge level is below $40 \%$, drivers receive 10 minutes of free rental to re-charge the vehicle. The battery does not have to be recharged before the Car2go is rented again: if the charging level is at least 50\%, the vehicle is available to the next customer." [3] [12].

The electric vehicles are equipped with advanced technology, which works through intelligent transport systems, the rental operations being carried out automatically, in a convenient and easy way, they are equipped with Lithium-ion batteries, they have on board GPS systems, radio and air conditioning. They reach the maximum speed of $135 \mathrm{~km} / \mathrm{h}$ and have the automatic gearbox, and insurance, fuel taxes and parking are included in the rental price.

The tariff model applied is very affordable and recommended to be used in other cities as well.

"One minute of driving a Car2go motor vehicle costs 29 cents, the hourly rate is $€ 12.90$, and the rate per day is $€ 39$ (24 hours). If the Car2go motor vehicle is used for stops, nonfinancial stimuli are calculated (access to certain urban areas; restricted access lanes, etc.) special rate of 9 cents per minute (5.40 $€$ per hour). The next few kilometers will cost 29 cents per kilometer." [3] [12].

Local or national public authorities in Holland provide financial incentives for this type of project (subsidies on the purchase of motor vehicles; differentiated fees; reduced taxes; free or differentiated parking spaces).

\subsection{Research project Oslo, Norway}

The project was carried out when Norway was considered at that time, the state with the most electric vehicles in Europe. It is the vogue of 2012, when on the road arteries of Norway "there were 6,587 units circulated, with a population of 5 million inhabitants" [3] [12].

The legislative facilities in Norway at that time, for electromobility, were as follows [3] [12]:

$\checkmark$ Free access on paid roads;

$\checkmark$ VAT (25\%) does not apply to vehicles;

$\checkmark$ The "first registration tax" for new vehicles does not apply;

$\checkmark$ Permission to travel on the lanes reserved for buses and taxis;

$\checkmark$ Free parking in public spaces, with the need to respect the maximum allowed parking time;

$\checkmark$ Exemption from payment for electric motor vehicles on local ferries.

Incentives have been instrumental in the sustainable development of the use of this type of motor vehicles in Norway.

The research carried out in this project showed that the population of Norway was very interested in electromobility at that time.

"With an open heart we describe Norway as the world leader in the use of electric motor vehicles and Oslo as the motor vehicle capital of the world, with the highest density of electric motor vehicles compared to any capital" [3] [12].

\section{Results of these projects and the current status regarding their applicability at European level} On December 11, 2019, the European Union, through the European Parliament, set the conditions for $\mathrm{CO}_{2}$ emissions reduction through the Green Deal or the European Ecological Pact [17]. This document is based on a whole series of initiatives and policies through which the European Commission aims to make the European continent a neutral area in terms of climate and pollution by the year 2050 .

The European Green Deal is the 'EU roadmap to a sustainable economy' and sets out the following headline targets [14]:

$\checkmark$ That by 2050, the European Union will no longer emit greenhouse gases;

$\checkmark$ Economic growth to be decoupled from resource use; 
$\checkmark \quad$ No person or place will be left behind.

"By adopting the European Green Deal announced in December 2019, the EU is now aiming to reduce greenhouse gas emissions from transport by $90 \%$ by 2050 compared to 1990 levels, as part of a broader effort to transform itself into a climate-neutral economy. A key element of the effort to reduce emissions from road transport is the transition to alternative, lower-carbon fuels. Electricity is the most commonly used new source of these fuels, especially for passenger motor vehicles" [9].

In order to achieve these objectives, the amount of 1,000 billion euros was allocated, and from 2035 it is completely forbidden to sell new vehicles on petrol, diesel, hybrid or plug-in hybrid [14].

"The Green Deal mentions that an estimated 13 million zero and low-emission vehicles should be in circulation on European roads by 2025" [9].

So, the future of transport is green. The population must be educated and persuaded, at the same time, to readjust their mobility needs to other means of transport. For this they will have to overcome the reluctance and increase the attractiveness towards electric vehicles, currently the only viable option to their mobility needs and environmental requirements.

However, on this date, the characteristics related to the autonomy and charging times of the electric batteries, the high price at the purchase, the existence, the number and the power of the charging stations on the route and the higher weight of the electric vehicles, as a result of the additional electrical equipment (electric engines, electric batteries and related equipment), make them still unattractive among the consumers of electromobility.

In 2020, the SARS-COV-2 Coronavirus pandemic has strongly affected the economies of the world's countries. However, although their percentage in car parks is still low, registrations of electric vehicles in the European Union have continued to increase. In this regard, more than 500,000 electric vehicles have been registered, according to the data presented by ACEA [13].

"2020 has been disastrous for the automotive market in general, but extremely good for electric vehicles. Thus, 538,000 electric vehicles were registered in the EU, 117\% more than in 2019, and in Romania the increase was from 1,506 to 2,837 units. The largest market was Germany, with 195,000 units, followed by France with 111,000. Holland was on three, with 71,000, and of the non-EU countries, Norway and the United Kingdom are the best, with 76,000 and 108,000 electric vehicles" [13].

The registration situation of electric and hybrid re-chargeable vehicles at EU level in the period 2014-2020 (after the implementation of the Project Electric Vehicle Network in Urban Europe URBACT II, (EVUE)) [9][10] is presented in Table 1.

Table 1. The situation of electric and hybrid rechargeable vehicles registered at EU level between 2014 and 2020 (units) [8]

\begin{tabular}{|c|c|c|c|c|c|c|c|c|}
\hline $\begin{array}{c}\text { Year of } \\
\text { registration }\end{array}$ & $\mathbf{2 0 1 4}$ & $\mathbf{2 0 1 5}$ & $\mathbf{2 0 1 6}$ & $\mathbf{2 0 1 7}$ & $\mathbf{2 0 1 8}$ & $\mathbf{2 0 1 9}$ & $\mathbf{2 0 2 0}$ & $\begin{array}{c}\text { Grow } \\
\mathbf{2 0 1 4} \\
\mathbf{2 0 2 0} \\
\mathbf{\%}]\end{array}$ \\
\hline $\begin{array}{c}\text { Vehicle type } \\
\text { Electric with } \\
\text { battery }\end{array}$ & 75.067 & 119.222 & 164.681 & 244.231 & 376.534 & 616.644 & 904.262 & 1.105 \\
\hline $\begin{array}{c}\text { Rechargeable } \\
\text { hybrid }\end{array}$ & 56.758 & 126.032 & 191.561 & 254.249 & 349.181 & 474.724 & 755.282 & 1.231 \\
\hline
\end{tabular}

"Compared to the market situation at the time of the adoption of the Directive, the market for electric vehicles has matured strongly, especially in the case of light electric vehicles and buses (both 
battery electric and plug-in hybrid). In particular, electric vehicles have seen a rapid increase in terms of the total number of vehicle registrations and the number of models available between 2010 and 2020. In the third quarter of 2020, the percentage increased to $9.9 \%$ of total motor vehicle sales, compared to $3 \%$ in the previous year" [8][15].

"Although the percentage of the fleet is still low, a further acceleration of the assimilation of these vehicles to the market is expected, also driven by the need to comply with the legal requirements imposed by the $\mathrm{CO}_{2}$ emission performance standards for light-duty vehicles" [8][15].

As regards the infrastructure for charging electric motor vehicle batteries, a number of projects have been developed on the basis of which a lot of research has been done at European level. According to AVERE (European Association for Electric Vehicles with Batteries, Hybrid and Fuel Cells), a development plan has been established on initiatives to standardize the parameters of electric charging for infrastructure, as follows [2]:

$\checkmark$ End of 2011: ETSI \& CEN-CENELEC provided their recommendations to the European Commission for a European standard;

$\checkmark$ End of 2013: a DC standard is launched by the IEC;

$\checkmark$ 2017: ACEA position on Module 3 (standard or accelerated charging with special socket for multi-pin electric vehicles with control and protection functions on a specific circuit), Type 2 (single-phase and three-phase couplers for vehicles) \& Type 2 of accelerated charge 2/Combo 2 (Mennekes socket - Rated at 70A for single-phase voltage and $63 \mathrm{~A}$ for three-phase voltage, with a max. voltage of $500 \mathrm{~V}$, with 7 pins).

"As the autonomy of electric vehicles is generally lower - around $380 \mathrm{~km}$, an average calculated for 10 electric motor vehicles currently sold on the market - compared to that of traditional vehicles, electric vehicles need to be charged more frequently. The charging time depends on the capacity of the vehicle battery and the charging point (see Table 3.2). While "slow" and "normal" chargers are more suitable for home and workplace charging cycles, "fast" and "ultrafast" chargers are more suitable for highways and major road networks. The constraints imposed by autonomy and concern about the availability of charging stations along the route can lead to "autonomy and queue-in-line anxieties" among electric vehicle users: the fear that their vehicle will not have enough autonomy to reach its destination, and that charging may involve long queues if a station is already occupied" [9].

The situation regarding the charging technologies available in the EU, existing on that date, are presented in Table 2 .

Table 2. Charging technologies available in the EU at the level of 2021 [9].

\begin{tabular}{|c|c|c|}
\hline Charger speed and type & Rated power & Approximate loading time* \\
\hline$\underline{\text { Slow (single phase AC) }}$ & $\underline{3-7 \mathrm{~kW}}$ & $\underline{7-16 \text { ore }}$ \\
\hline Normal (three-phase AC) & $\underline{11-22 \mathrm{~kW}}$ & $\underline{2-4 \text { ore }}$ \\
\hline$\underline{\text { Fast (DC) }}$ & $\underline{50-100 \mathrm{~kW}}$ & $\underline{30-40 \text { minutes }}$ \\
\hline Ultrafast (DC) & $>100 \mathrm{~kW}$ & $<20$ minutes \\
\hline
\end{tabular}

* It also depends on battery capacity and other variables.

Figure 3.1 shows the status of the development of electric vehicle power supply infrastructure at the level of September 2020 by presenting the number of public charging points in absolute figures and their ratio per $100 \mathrm{~km}^{2}$ (EU-27 and The United Kingdom). 


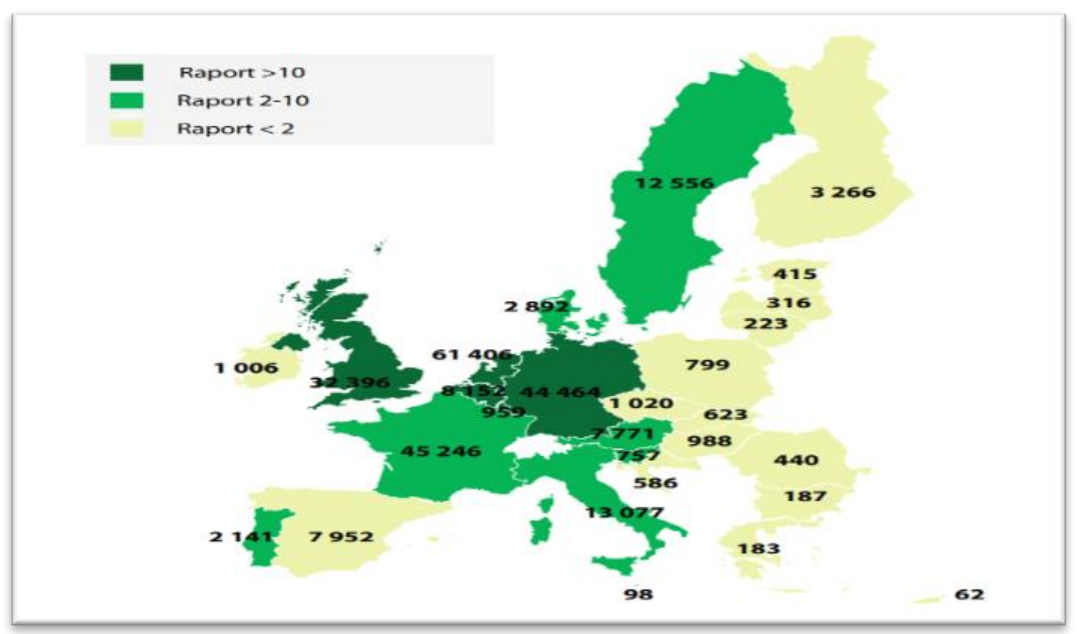

Figure 5. Number of public charging points at the level of September 2020 in absolute figures and their ratio per $100 \mathrm{~km}^{2}$ (EU-27 and the United Kingdom) [9].

\section{Conclusions}

At European level, especially in Eastern European countries, the level of greenhouse gas pollution is still high. This is the result of the massive exodus of polluting vehicles purchased second-hand from Western countries. The standard of living, the existing economic and social conditions at the level of these countries, does not allow a large mass of the population to purchase new, clean vehicles. In order to solve this problem and meet the requirements of the European policy on the decarbonization of transport, the authorities in these countries will have to act as urgently as possible through financial incentives, subsidies, legislative constraints, information of the population, other methods, in order to induce the users of the means of transport to turn to other means or ways of travel more efficiently, more environmentally friendly, in order to reduce or even stop pollution.

Interventions on infrastructure and improvement of traffic values in urban areas will also be needed. We believe that the solution to these problems lies in reshaping the architecture of streets and intersections, by building roundabouts in large busy intersections (roundabouts have an efficiency in traffic congestions up to $60 \%$ ), widening (where possible) streets and boulevards by adding additional lanes for slow vehicle traffic.

Another way of solving traffic problems can be solved by developing and using intelligent means of traffic management. On this date, it appears from the research carried out that there are technological possibilities in this regard by installing in traffic the information panels and directing the flows of vehicles to less crowded traffic arteries, smart traffic lights, etc.

Projects within the Urban Europe Electric Vehicle Network - URBACT II, (EVUE) have remained unapplied on a large scale and at the level of other states. Their application at European level in all countries, including eastern European countries, is more than necessary and timely. In order to be applied in a uniform manner at the level of EU countries, projects could be financed through repayable loans. In this respect, the authorities of these countries must carry out fundraising projects. However, in the period following the programme's research, registrations of electric and plug-in hybrid vehicles continued to increase despite the high price for purchase, the low autonomy of electric batteries and the electricity supply network, which is deficient.

The granting by European states of subsidies on electricity to all users of electric vehicles is more than necessary. This would contribute to the attractiveness of electromobility.

In the case of many Eastern European countries, the electricity comes from non-renewable sources (thermal power plants and other sources - about 60\%). It is very important that all charging stations are powered by renewable energy. This would make electric vehicles much more efficient from the point of view of pollution. 
"Programmes to expand renewable energies need to be accelerated in parallel with the increasing demand for electricity for electric motor vehicles. This requirement should be part of the next revision of the targets for the expansion of renewable energies" [4] [12].

Electric vehicles are not noticed in traffic by pedestrians, they cause fear among them and road events can happen. The equipment by the manufacturers of all the electric vehicles with sound generators in order to be noticed in the urban traffic by pedestrians is needed.

"There are also certain fears that electric vehicles could be dangerously quiet on the roads - in this case, it may be necessary to impose minimum artificially generated noise levels so that pedestrians and other road users can be audibly warned of the presence of an approaching vehicle" [4] [12].

Since charging stations with electric energy by induction have recently appeared, older electric vehicles are not adapted to use such charges of accumulator batteries. Design and installation in urban car parks, supermarkets and other objectives of major importance of induction charging stations, while adapting and making the charging system on vehicles compatible. In this way charging becomes more convenient, eliminating the use of connection cables to the charging station. The charging is carried out by simply positioning the vehicle over the device mounted on the horizontal surface of the parking lot (such devices have been tested and work very well in the parking lots of the airport in Frankfurt Germany);

It is necessary to install personalized charging stations in parking lots, specially designed for owners of electric vehicles who are disabled people. For those persons, additional subsidy would be required when purchasing that type of vehicle.

Facilities and the granting of subsidies for the purchase of home charging devices for home users are needed to be made by the authorities of European states.

In order to educate, inform and guide the citizens who live jointly, at the block of flats, towards electromobility, it is necessary to equip the parking lots between the blocks of flats with charging stations for electric vehicles. Installation of charging stations (including induction charging) related to the parking lots paid for by household users living jointly, at the block of flats;

Gradual reduction of subsidies granted by state authorities until the final phase out for classic motor vehicles, simultaneously with the development of the electromobility process;

"Similarly, to encourage the purchase of electric vehicles, it will be necessary at least to eliminate any cost advantage presented by petrol vehicles, through appropriate differentiated taxation regimes and, perhaps, in the early years, to favour electric vehicles to boost the market. In principle, electric vehicles should have a lower cost of use due to the fact that the electric engine is much more efficient. Of course, however, many things will depend on the structure of electricity tariffs and the possibility of integrating battery recharging into an intelligent system for balancing the electric charge at a preferential tariff. The EESC calls for econometric studies to be carried out at an early date on the various possible options for this purpose. Given that the transition to a electric vehicle is a major step for the consumer, there may be a need for strong encouragement, especially in the early years of the transition (e.g. through a strong price difference in the purchase charge in favour of the electric vehicle compared to classic engine vehicle)" [4] [12].

It is necessary to consolidate and develop the project of "Smart Road", where the electric vehicle can charge on the go (in Sweden there are already built two kilometers of road that can charge electric vehicles on the go).

We have noticed the lack of programmes to popularize electric vehicles among the population of Eastern European countries.

"In order to successfully move on to the next stage and strengthen consumer demand and trust, there are a few requirements that can be rendered through the following main aspects - safety, reliability, performance and design, autonomy and flexibility, easy recharge, purchase price and cost of use" [4] [12]. 


\section{References}

[1] Green Card, (2007), Towards a culture of urban mobility, Commission of the European Communities, Brussels, September 25, 2007, COM(2007) 551 final, accessed on July 14, 2021 trough: https://op.europa.eu/ro/publication-detail/-/publication/343c0af6-e5a9-4a4a-82999556756d 95fa/language-ro.

[2] Noon, M., (2012), Electric vehicles in urban Europe, EVUE - approaches to e-mobility infrastructure. Urb Act -Connecting Cities - Building Success, EU - Stakeholder Guide Infrastructure, Brussels, pp 1-88.

[3] Rodrigues, O., (2012), Electric vehicles in urban Europe, EU- Guide for Stakeholders, EVUE Business models, European Regional Development Fund, Lisbon, 2012, pp 1-88, accessed on July 14, 2021 trough:

https://urbact.eu/sites/default/files/import/Projects/EVUE/documents_media/EVUE_Final_Repo rt_October_2012-RO_ok.pdf.

[4] Sepi, M., (2011), The road to wider ese of electric vehicles, Journal article, Opinion of the European Economic and Social Committee (exploratory opinion requested by the Presidency (EESC), Official Journal of the European Union, Publisher: EUR-lex, Issue: 2011/C44/08, pp. 47-52, accessed on July 14, 2021 trough: https://eur-lex.europa.eu/legalcontent/RO/TXT/?uri=CELEX:52010AE0989

[5] The European Commission, (2007), Towards a new culture of urban mobility, Green Books, Publisher: European Parliament, Communication from the Commission-Presentation, Brussels, 2007, $\operatorname{COM(2207)~} 551$ final -SEC(2007)1209, p.8, accessed on July 14, 2021 trough: https://eur-lex.europa.eu/legal-content/RO/TXT/?uri=CELEX:52013DC0913

[6] The European Commission, (2018), A clean planet for everyone. A long -term strategic European vision for a prosperous, modern. Competitive and climate-neutral economy, Communication from the Commission to the European Prliament, the Council, the European Economic and Social Committee and the Committee of the Region, Report, COM 773 final.

[7] The European Commission, (2020), The strategy for sustainable and smart mobility - putting European transport on the path to the future, Communication from the Commission to the European Parliament, the Council, the European Economic and Social Committee and the Committee of the Region, Report, COM(2020) 789 final-SWD (2020) 331 final (19.12.2020), Brussels;

[8] The European Commission, (2021), Report from the commission to the European Parliament and the Council, on the application of Directive 2014/94/EU on the instalation of infrastructure for alternative fuels, Brussels, March 08, 2021, COM(2021) 103 final, \{SWD(2021) 49 final \}, p. 2, accessed on July 14, 2021 trough: https://data.consilium.europa.eu/doc/document/ST-68412021-INIT/ro/pdf.

[9] The European Commission, (2021), Special Report, Loading infrastructure for electric vehicles: the number of charging stations has increased, but inhomogeneous level of infrastructure installation complicates travel within the EU. Brussels, 2021, pp. 1-51, accessed on July 14, 2021 trough:

https://www.eca.europa.eu/Lists/ECADocuments/SR21_05/SR_Electrical_charging_infrastructure_RO.pdf.

[10] https://ec.europa.eu/programmes/horizon2020/sites/default/files/H2020_RO_KI0213413RON.pdf

[11] https://urbact.eu/evue

[12] https://urbacteu/sites/defaultfiles/importProjects/EVUE/documents_media/EVUE_Final_Report_October_2012-RO_ok.pdf.

[13] https://economie.hotnews.ro/stiri-auto-24582982-vandut-anul-trecut-peste-500-000-masini-electrice-diesel-scazut-32-iarvanzarile-masini-benzina-37-cum-sta-romaniahtm.

[14] https://greendeal.ro/green-deal-pactul-ecologic-european-prezentare.

[15] https://www.acea.auto.

[16] https://eur-lex.europa.eu/legal-content/RO/TXT/?uri=CELEX\%3A32019R0631

[17] https://eur-lex.europa.eu/legal-content/EN/TXT/?uri=COM\%3A2019\%3A640\%3AFIN 